\title{
Restenosis after coronary angioplasty: a proposal of new comparative approaches based on quantitative angiography
}

\author{
Patrick W Serruys, David P Foley, Pim J de Feyter
}

Thoraxcenter,

Erasmus University,

Rotterdam,

The Netherlands

$P$ W Serruys

D P Foley

P J de Feyter

Correspondence to

Prof P W Serruys,

Erasmus University Ee 2332,

PO Box 1738,

3000 DR Rotterdam,

The Netherlands.

Accepted for publication

12 May 1992
Recurrence of coronary artery stenosis or "restenosis" is now well established as the main limitation of percutaneous transluminal coronary angioplasty (PTCA), which was first used by Gruentzig in $1977 .{ }^{1}$ However, despite the increasing popularity and application of the percutaneous approach to coronary revascularisation as an attractive alternative to coronary artery bypass graft surgery and the apparent frequency of lesion recurrence there is still no satisfactory universally accepted "definition of restenosis" (table). ${ }^{2-13}$ New devices for percutaneous coronary recanalisation (endoluminal coronary stent implantation; directional, extractional, or rotational atherectomy; laser balloon angioplasty; and excimer laser) have up to now, failed to provide better long term outcome than balloon angioplasty. ${ }^{14-17}$ but they have stimulated the search for universally applicable, objective methods of assessing the new methods and of comparing them with conventional balloon angioplasty and with each other in terms of the immediate and long term effects on treated vessels. ${ }^{15}$

Nearly all the early reports on restenosis after angioplasty relied on visual or userdependent analysis of cineangiograms, ${ }^{2-5910}$ approaches that are of undoubted clinical value. None the less, the results of these early clinical studies must now be re-examined in the light of information provided by recent technological advances in image acquisition and description, as well as revascularisation hardware.

A selection of different criteria for angiographic restenosis that have been used or are used to describe the outcome of clinical studies

(a) Loss at follow up of at least $50 \%$ of the initial gain after PTCA (NHLBI 4).

(b) A return to within $10 \%$ of the pre-PTCA diameter stenosis (NHLBI 3). ${ }^{3}$

c) An immediate post-PTCA diameter stenosis $<50 \%$ that increases to $\geqslant 50 \%$ at follow up. ${ }^{34}$

(d) As for 3 above, but a diameter stenosis $\geqslant 70 \%$ at follow up (NHLBI 2).

(e) Loss of $\geqslant 20 \%$ diameter stenosis from post PTCA to follow up. ${ }^{6}$

$(f)$ Loss of $\geqslant 30 \%$ diameter stenosis from post PTCA to follow up (NHLBI 1).

(g) A diameter stenosis $\geqslant 50 \%$ at follow up.

(h) A diameter stenosis $\geqslant 70 \%$ at follow up.

(i) A diameter stenosis $\geqslant 70 \%$ at follow

(i) Area stenosis $\geqslant 85 \%$ at follow up.

(k) Loss $\geqslant 1 \mathrm{~mm}^{2}$ in stenosis area from post-PTCA to follow up.

(m) Diameter stenosis $>50 \%$ at follow up after successful dilatation of a lesion (defined as

Diameter stenosis $>50 \%$ at follow up after successful dilatation of a lesion (defined as
diameter stenosis $<50 \%$ and a gain of $>10 \%$ in luminal diameter immediately after diameter stenosis $<50 \%$ and a gain of $>10 \%$ in luminal diameter immediately a
PTCA). Lesions with a $<10 \%$ increase in diameter stenosis since PTCA are not included. ${ }^{13}$

(NHLBI 1, 2, 3, and 4 are four different criteria for angiographic restenosis, as defined by the National Heart, Lung, and Blood Institute of the United States.)

The advent of quantitative coronary angiography, which has been pioneered at the Thoraxcenter ${ }^{18-20}$ (and is becoming increasingly available with the development of digital cineangiographic equipment for the catheterisation laboratory), has opened up a new approach to clinical restenosis studies. We now describe the evolving concept of "restenosis" through our experience with quantitative coronary angiography over the past ten years, ${ }^{20-35}$ and we propose two new approaches to its assessment by absolute luminal diameter measurements obtained by quantitative coronary angiography (a) "matching" and (b) relative gain, relative loss, and net gain index.

\section{Restenosis: definition difficulties}

There are at least 13 different "definitions" of restenosis based on coronary angiography (table). The use of these mainly arbitrary categoricalcut-offpoints, differentangiographic follow up rates $(57-100 \%)$, and visual assessment of the coronary angiogram by most investigators (a method that considerably overestimates lesion severity before PTCA and underestimates luminal narrowing immediately after intervention), ${ }^{36}$ largely explains the variability $(12-55 \%)$ of the reported "incidence of restenosis" (fig 1). Applying three different and frequently used definitions to a series of 490 lesions serially measured during six months follow up, we showed that ( $a$ ) the greatest single determinant of the restenosis rate was the definition applied (fig 2A) and (b) even if the eventual incidence of restenosis was similar, different definitions identified different patient populations (fig 2B), making risk factor determination impossible. These factors are almost certainly responsible for most of the confusion surrounding the concept of restenosis after PTCA.

Though some widely used restenosis criteria are based on historical physiological concepts, ${ }^{37}$ the measurement used is percentage diameter stenosis, which is calculated by assuming a "normal" diameter value for the segment of coronary vessel immediately proximal or distal to the area of interest and using it as a reference. This assumption has been shown to be invalid, particularly in the context of multivessel 
Figure 1 Restenosis rates from a selection of published studies with different angiographic follow up rates intervals (1-9 months), 11 different restenosis criteria and various angiographic analysis techniques. (57-100\%), follow-up

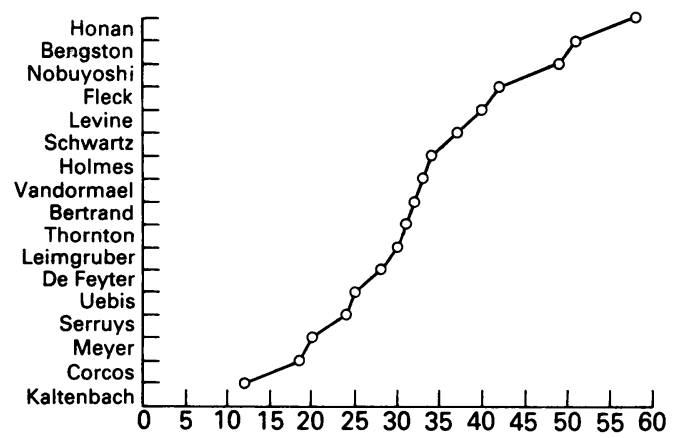

Restenosis rate in published reports (\%)

disease, when there is virtually always diffuse intimal and/or subintimal thickening ${ }^{38}{ }^{39}$ as well as variable age-related or compensatory ectasia, ${ }^{40}$ and after interventions when the "reference diameter" may become affected by the restenosis process. ${ }^{27}{ }^{41}$ Approaches that use the percentage diameter stenosis are therefore inherently flawed, both by the computation method and by the inability of a single measurement in time to describe accurately what is essentially a "moving target", as has been shown independently (and almost simultaneously) by our group ${ }^{11}$ and by Nobuyoshi $e t$ $a l^{12}$ (fig 3). Both groups used predetermined serial angiographic follow up at one, two, three, four and six months to show that luminal renarrowing occurs to some degree in all lesions that are dilated and that it is a continuous, time-related phenomenon which rarely occurs after six months.

Quantitative angiographic studies have clearly and definitively shown that absolute measurements such as mean luminal diameter, minimal luminal diameter, or the minimal cross sectional area of stenosis provide more reliable and meaningful information than percentage diameter stenosis on the haemodynamic significance of an obstructive coronary lesion. ${ }^{24-2629}$ Of all the measurements directly acquired by quantitative angiography, the absolute value of the minimal luminal diameter

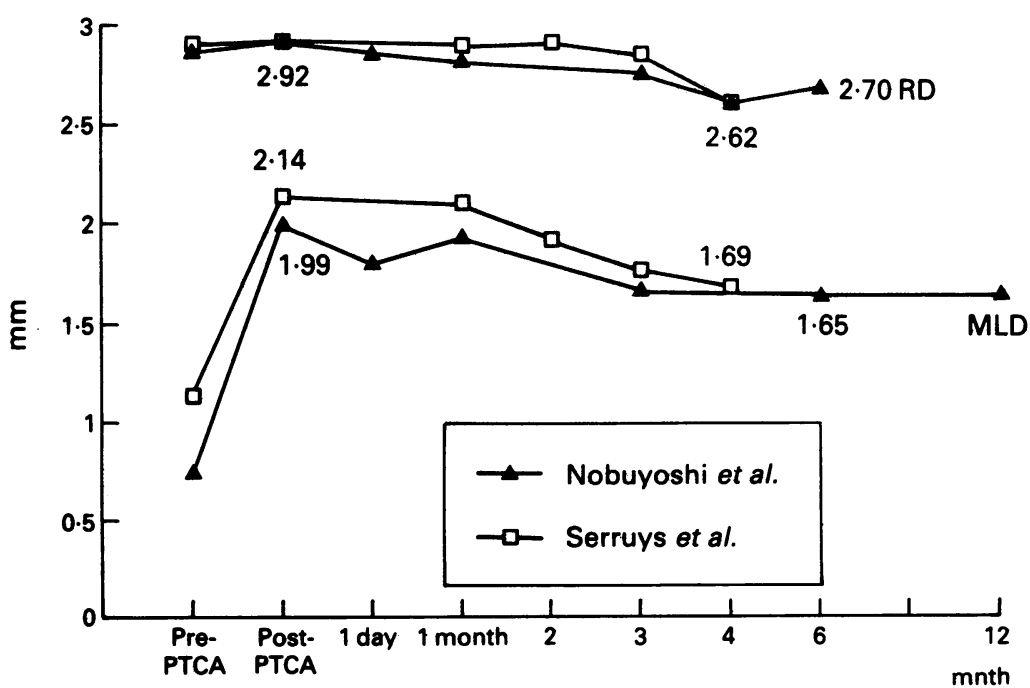

Figure 3 Minimal luminal diameter (MLD) and reference diameter ( $R D$ ) measurements reported in the studies of Nobuyoshi et al' and Serruys et al," showing virtually identical time trends during six month follow up.

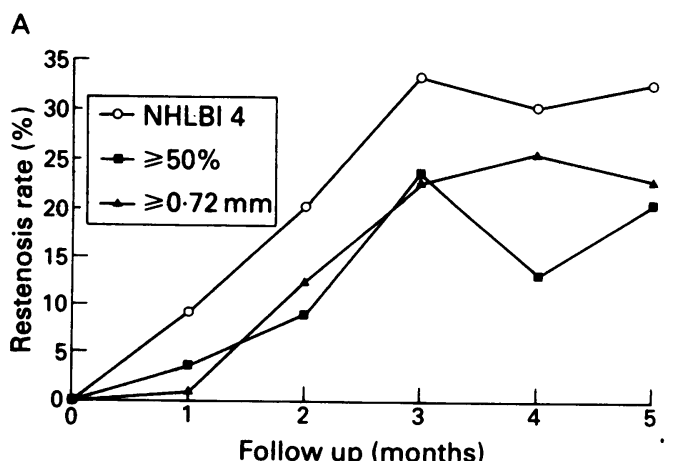

B

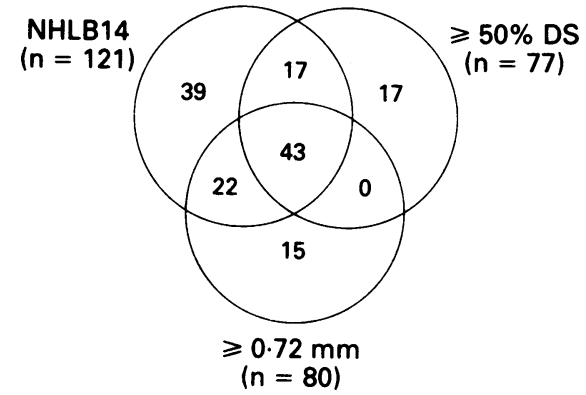

Figure 2 (A) Cumulative incidence of restenosis (defined by three different criteria) during a five month follow up in 490 successfully dilated lesions. NHLBI 4, criterion 4 of the National Heart, Lung and Blood Institute of America (loss of $>50 \%$ of the initial gain at angioplasty) $; \geqslant 50 \%, \geqslant 50 \%$ diameter stenosis at follow-up; $\geqslant 0.72 \mathrm{~mm}, 0.72 \mathrm{~mm}$ loss in minimal luminal diameter between post angioplasty and follow up (reproduced with permission from Circulation 1988;77:361-71. (B) Venn diagram showing the distribution of lesions fulfilling the different criteria applied in fig $2 A$. Of a total of 153 lesions showing restenosis according to at least one of the three criteria applied, only 43 fulfil all three. (Reproduced with permission from Circulation 1988;77:361-71"1).

has been shown to be the greatest single determinant of the haemodynamic consequences of a stenosis, because this measurement affects blood flow by a fourth power term. ${ }^{2642} 43$ It is therefore the most unambiguous, objective, and reproducible measure to describe the calibre of coronary vessels and changes caused by interventions. All important multicentre trials examining the impact of various pharmacological agents on restenosis after PTCA are now assessed in a core laboratory, ${ }^{44-46}$ by quantitatively derived indices-particularly minimal luminal diameter. ${ }^{47}$

Our group has previously recommended the standards required for clinical studies, including sufficient patient numbers, the use of quantitative coronary angiography, $100 \%$ angiographic follow up, and restenosis criteria that reflect a significant change in minimal luminal diameter from intervention to follow up. ${ }^{48}$ In addition, in a recently published quantitative angiographic study we highlighted the distinction between "clinical" and "angiographic" restenosis, ${ }^{49}$ illustrating the dangers of misinterpretation of the results of restenosis studies if observations are based solely on conventional restenosis criteria (for example, $>50 \%$ diameter stenosis at follow up angiography) without knowledge of the actual changes in luminal dimensions during and after angioplasty. The outcome and conclusions of this study underline the need to define end 


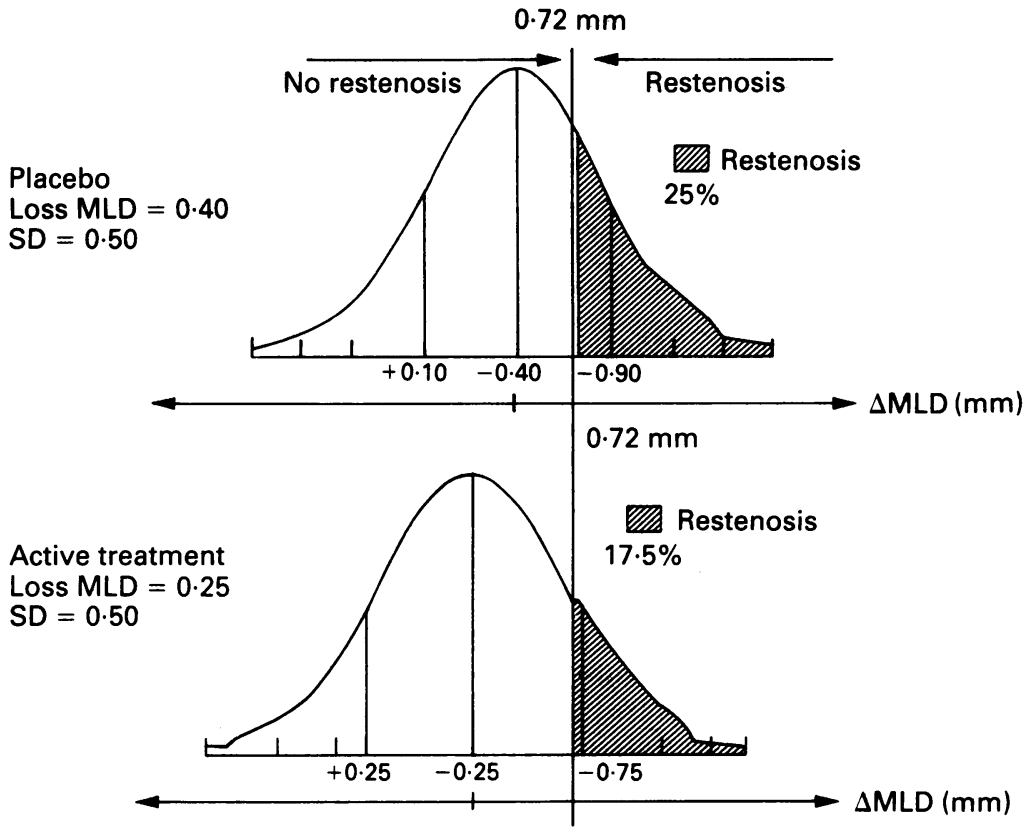

Figure 4 Gaussian model of restenosis in the placebo and treatment groups. The lower curve represents a 30\% reduction in the mean deterioration in minimal luminal diameter during follow up $(-0.25 \mathrm{~mm} v-0.40 \mathrm{~mm})$ in the treated group. The upper curve shows the distribution of the change in minimal luminal diameter ( $\triangle M L D$ ) found at follow up in a prospective study at the Thoraxcenter." To show the significance of this difference requires 233 patients per group. Whereas if a deterioration in minimal luminal diameter of $0.72 \mathrm{~mm}$ is taken as the cut-off point for restenosis (as shown by the hatched area) 620 patients per group are required. See text for full explanation. (Reproduced with permission of Hogrefe and Huber from Interventional Cardiology. ${ }^{59}$ )

points for clinical restenosis studies, which we believe must be described as the change in the minimal luminal diameter of the treated lesion immediately after angioplasty (or other intervention) and at follow up.

\section{New criteria for restenosis based on minimal luminal diameter}

To develop criteria for restenosis based on the change in minimum luminal diameter seen during follow up, our group measured the long term variability in lesion measurement-ie, $1 \mathrm{SD}(0.36 \mathrm{~mm})$ of the difference between the

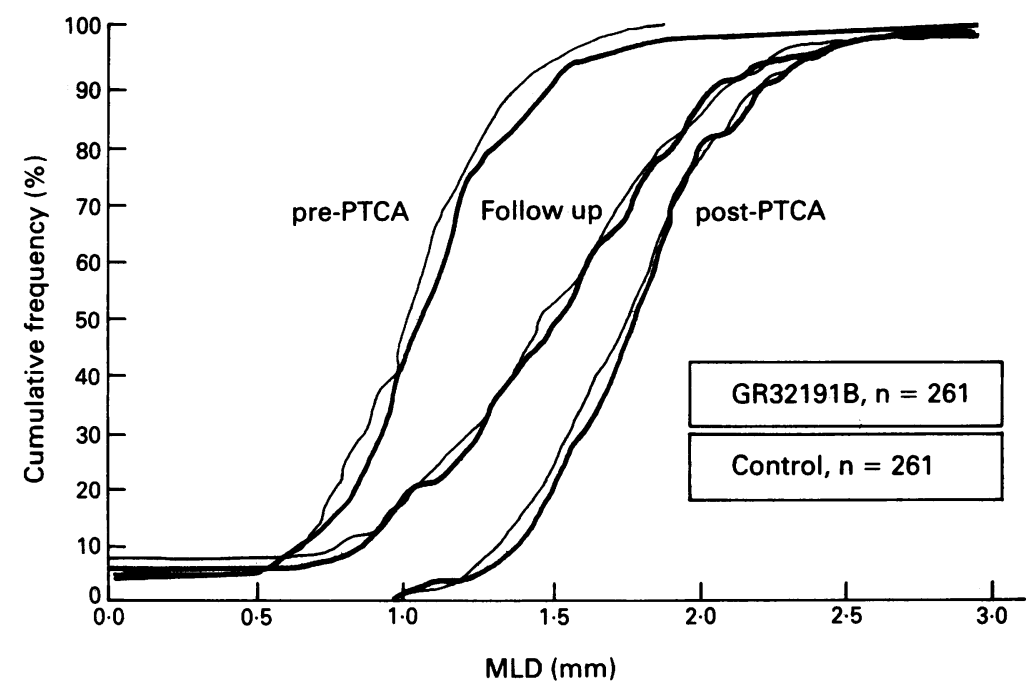

Figure 5 Cumulative frequency (distribution) curves of absolute minimal luminal diameter measurements pre-PTCA, post-PTCA, and at follow up in control (light curves) and treatment groups (heavy curves) for the CARPORT restenosis prevention trial. Virtual superimposition of the curves shows that the groups had similar values for minimal luminal diameter, and that treatment caused no identifiable benefit. (Reproduced with permission from Circulation 1991;84:1568-81.44) means of minimal luminal diameter measurements taken from coronary angiograms of the same lesions 90 days apart when no intervention had been carried out. ${ }^{23}$ The actual mean difference in minimal luminal diameter over that period was $0 \mathrm{~mm}$, implying no detectable disease regression or progression that might influence results during the 90 days. The long term variability thus reflects the long term random variation in lesion measurements using the computer assisted analysis system (CAAS). One standard deviation includes $68.3 \%$ of the measurement variability and $2 \mathrm{SDs}$ account for $95.5 \%$. Therefore a difference in minimal luminal diameter of more than twice the longterm variability can be regarded as indicative of significent change-that is, as a division between restenosis and no restenosis.

Ellis and Muller ${ }^{50}$ pointed out several limitations to this definition of restenosis that we had previously recognised. ${ }^{48}$ Criteria based on absolute changes in minimal luminal diameter did not take blood vessel size into account because the study of variability was performed on vessels with an average reference diameter of $3.7 \mathrm{~mm}^{23}$ whereas, in two recent large European multicentre restenosis prevention trials the mean diameter of the vessels that were dilated was $2.6 \mathrm{~mm} .^{44} 455152$ Studies using sliding-scale criteria to overcome this shortcoming have been completed and some initial results have been published. ${ }^{5153} \mathrm{We}$ will expand this concept later in this article.

\section{Restenosis: a continuous process}

Although reports of pathological studies ${ }^{54-57}$ and quantitative angiographic studies ${ }^{11227}$ showed that the process of intimal hyperplasia is a continuously distributed phenomenon, the outcome of trials of pharmacological prevention of restenosis and of trials of new interventional devices have been traditionally assessed by categorical cut off criteria for the occurrence of restenosis. When we examined the prospectively collected, carefully standardised, quantitative coronary angiographic data in 1234 patients (1445 lesions) treated by balloon angioplasty, with $91 \%$ angiographic follow up, we showed that luminal renarrowing after PTCA, whether assessed by minimal luminal diameter or percentage diameter stenosis, clearly follows a gaussian or normal distribution (fig $4^{52}$ ). This finding, like Kuntz et al's ${ }^{58}$ findings in patients undergoing atherectomy or stent implantation and previous angiographic evidence provided by our group ${ }^{1127}$ and Nobuyoshi et al,,$^{12}$ provided clinical confirmation of pathological observations and validates the application of parametric statistics to the assessment of restenosis. Furthermore, it shows the limitations of categorical criteria in the assessment of important clinical restenosis trials. There may be sound clinical reasons for selecting particular angiographic definitions of restenosis, but no cut-off point (even one shown to have a physiological basis ${ }^{37}$ ) can satisfactorily or accurately define a given measure of luminal renarrowing as "restenosis" because this is a continuous process and because there is no 
identifiable threshold of deterioration in lumen diameter after angioplasty above which physiological or clinical significance is reached.

It is much more realistic and meaningful, therefore, to study the overall effects of a pharmacological agent or revascularisation device in the treated population in terms of its mean effect on the expected loss of minimal luminal diameter for the group (as represented by the mean loss in minimal luminal diameter for the "placebo" or control group). This approach to statistical analysis also has significant implications in terms of the population size required for a valid clinical trial. In the example shown in (fig $5^{59}$ ) treatment reduces the mean loss in minimal luminal diameter during follow up after PTCA from $0.40 \mathrm{~mm}$ $( \pm 0.50 \mathrm{~mm})$ to $0.25 \mathrm{~mm}( \pm 0.50 \mathrm{~mm})-\mathrm{a} 30 \%$ reduction. If the process is viewed as continuous each treatment group must contain 233 patients if such a difference is to be measured as significant with a power of $90 \%$ and a $95 \%$ confidence interval. If a categorical approach (restenosis yes/no) is applied to the loss in minimal luminal diameter $(\geqslant 0.72 \mathrm{~mm})$, then the $0 \cdot 15 \mathrm{~mm}$ difference in minimal luminal diameter is equivalent to a reduction in the restenosis rate from $25 \%$ to $17 \cdot 5 \%$. To show that this difference is significant at the $95 \%$ confidence level requires 620 patients in each group ( $266 \%$ more patients than needed for the continuous approach).

We believe, furthermore, that the results of intervention trials are more clearly and elegantly presented as simple cumulative distribution curves to show the change in minimal luminal diameter during follow up in treated and control populations (fig $6^{44}$ ), or indeed in PTCA and stent or atherectomy groups..$^{580}$

New challenges and potential solutions with minimal luminal diameter

The considerable growth in new devices for coronary revascularisation has presented a new challenge in terms of how to describe immediate and long term angiographic outcome. We have tackled the challenge of "comparing the incomparable" by examining their "relative" merits or by confining comparisons to "matched" lesions-that is, lesions of similar severity in vessel segments of identical size and location (even though, contrary to popular belief, luminal renarrowing measured absolutely or as restenosis rates does not vary significantly throughout the coronary tree)..$^{53}$

Matching: a surrogate for randomisation The first method allows us to "compare the comparable" by "matching" the lesions in each treatment group according to three basic principles: (a) the angiographic dimensions of the matched lesions are assumed to be identical, (b) the observed difference between the two "identical" lesions must be within the range of reproducibility of the computer analysis system being used (for the CAAS system this is $\pm 0.1 \mathrm{~mm}$ ), and (c) the size of the vessels to be matched (interpolated reference diameter) is selected within a range of $\pm 3 S D(0.3 \mathrm{~mm})$, giving confidence limits of $99 \% .{ }^{15}$

In a recent observational study we compared the immediate angiographic results of balloon angioplasty, directional coronary atherectomy (DCA), and intracoronary stenting by this technique. ${ }^{15}$ Both DCA and stenting gave a significantly greater initial improvement in luminal diameter than PTCA. Figure 6A, adapted from a previous observational study, ${ }^{60}$ illustrates the application of matching to the comparison of immediate and long-term angiographic outcome after PTCA and DCA. Because the baseline angiographic measurements were similar, the approximate overall gain and loss in minimal luminal diameter can be easily derived from the figure. Though DCA was associated with a significantly greater initial improvement in minimal luminal diameter, the loss during follow up (restenosis) after DCA was also significantly greater than after PTCA, so that the ultimate outcome (minimal luminal diameter at follow up) was similar for both treatments. This technique was used to compare long term results after PTCA and stent implantation in a preliminary study of 93 matched lesions. Though stenting was associated with a greater loss in luminal
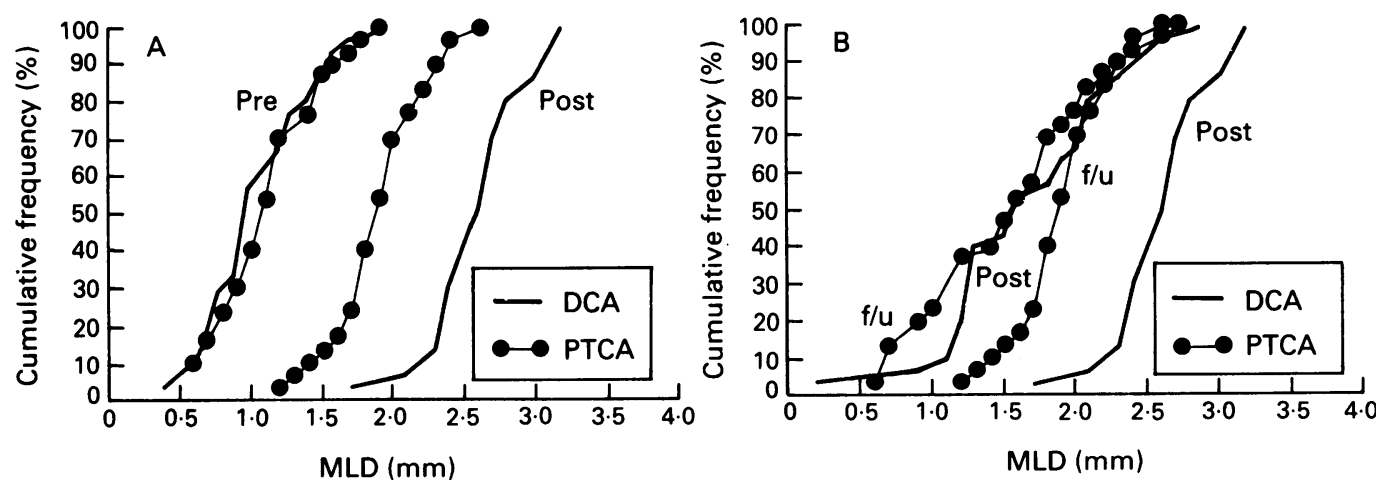

Figure 6 Cumulative frequency (distribution) curves comparing $(A)$ the immediate (pre-post) and (B) the follow up (post-follow up) effects of PTCA and directional coronary atherectomy $(D C A)$ on absolute minimal luminal diameter (MLD) values as measured by quantitative coronary angiography in "matched" coronary lesions. ( $A) D C A$ caused a much greater improvement in luminal diameter immediately after intervention. (B) Reduction of this advantage occurred during follow up so that there was little difference between the curves representing minimal luminal diameter at follow up after DCA and PTCA (see text for explanation). (Reproduced with permission from Am $J$ Cardiol 1991;68:1556-63 ${ }^{60}$ ). 
Figure 7 (A)

Scattergram of all the values for relative gain at balloon angioplasty and relative loss during follow up in a large multicentre restenosis prevention trial $^{4}$ for both placebo and treatment groups. There was an identical linear relation in both groups.

(B) Relation between relative gain and relative loss in MLD (from fig 7a) and vessel size (represented by the interpolated reference diameter). The slope of the graph for "relative loss" changed significantly where the vessel size is greater than $3.5 \mathrm{~mm}$ in diameter, suggesting less restenosis in larger vessels (see text for explanation). diameter during follow up it produced a significantly larger vessel lumen (reflected by a larger MLD) than PTCA at follow up. ${ }^{61}$

\section{Relative gain and relative loss: the} sliding-scale and the restenosis paradox The second method of comparison arose from the need to create sliding-scale criteria to assess the outcome of PTCA in vessels of different sizes; but it may also be used to compare different treatments. As previously explained, the concept of restenosis criteria based on a loss in minimal luminal diameter of $\geqslant 0.72 \mathrm{~mm}$ during follow up was developed in vessels with average reference diameter of $3.7 \mathrm{~mm}^{23}$ so, to overcome this limitation, the concepts of "relative gain" and "relative loss" were introduced to adjust for vessel size, by relating the absolute change in minimal luminal diameter after intervention and during follow up to the interpolated reference diameter of the coronary segment in question. 495153 The "net gain index" describes the ultimate outcome of intervention, by relating the net change in minimal luminal diameter from pre-treatment to follow up to the vessel size.

These simple calculations may be presented as follows:

Relative gain $=$ MLD post-intervention MLD pre intervention/vessel size.

Relative loss $=$ MLD post intervention MLD at follow up/vessel size.

Net gain index $=$ MLD at follow up - MLD pre intervention/vessel size.

Where MLD is the minimal luminal diameter and the vessel size is represented by the interpolated reference diameter of the lesion pre intervention.

A scattergram of the relative gain and relative loss values for the entire patient population in a recent, large, multicentre, restenosis prevention trial, ${ }^{45}$ shows a linear relation (coefficient of correlation $0.4, p<0.001$, with the lines of correlation for placebo and treatment groups being exactly superimposed (fig 7a). This graphic representation confirmed the outcome
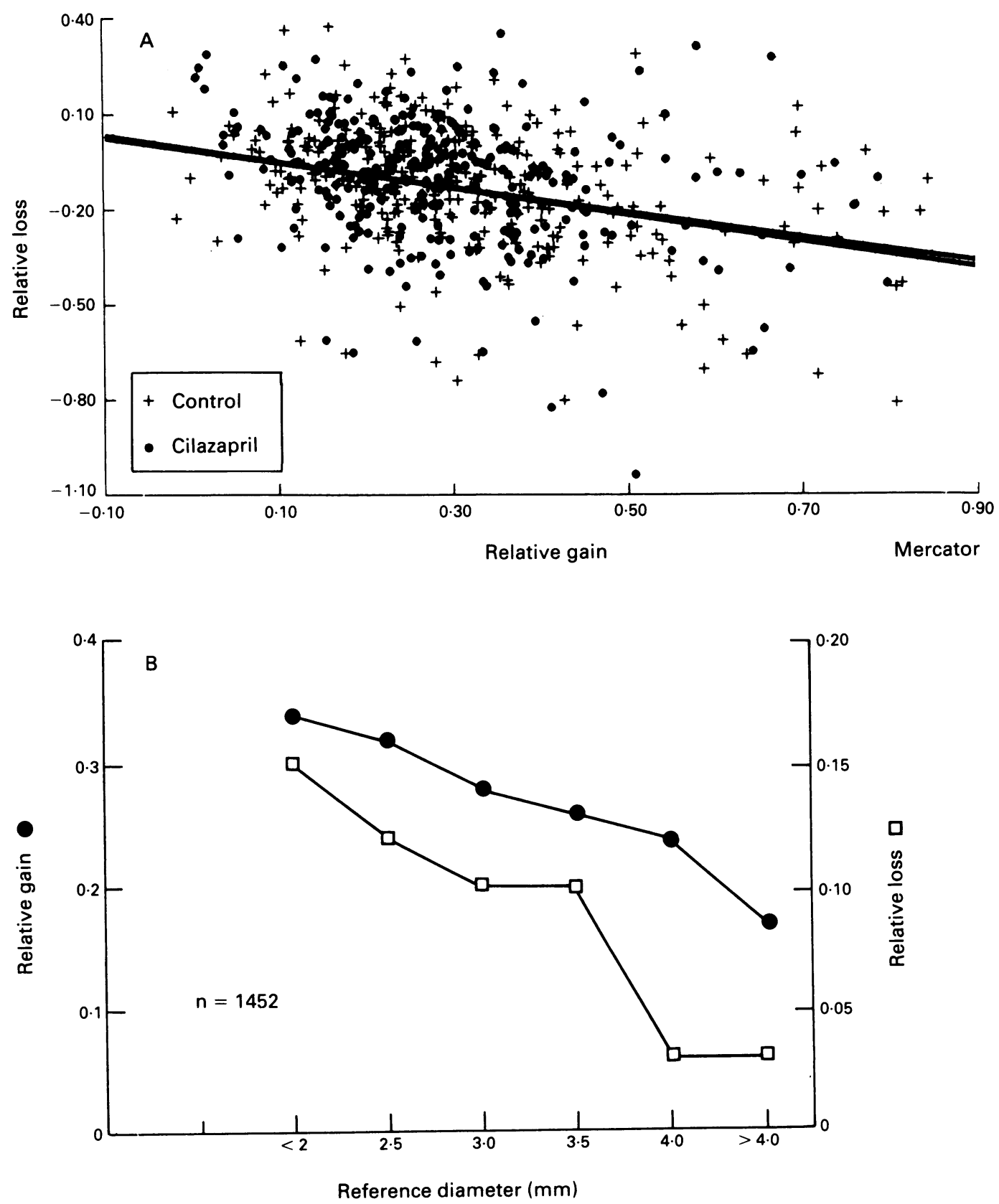
of the study that had been established with cumulative distribution curves (no demonstrable benefit from the pharmacological agent $^{45}$ ). More importantly, however, it showed the nature of relation between the relative gain (representing the permanent injury done to the vessel wall by balloon inflation(s)) and the relative loss (the angiographic correlate of intimal hyperplasia or "restenosis"). The regression lines show that the greater the relative gain in minimal luminal diameter achieved by dilatation the greater the subsequent relative loss (that is, a better initial result is subsequently associated with more restenosis). Stepwise multiple linear regression analysis of patient, procedural, and angiographic data from the CARPORT trial ${ }^{44}$ also showed that the relative gain is the strongest determinant of restenosis (defined as absolute change in minimal luminal diameter from postangioplasty to follow up).$^{51}$

This apparent paradoxical association of greater renarrowing of the lumen with greater degrees of luminal improvement by PTCA has recently been reported in a quantitative angiographic clinical study from our group, ${ }^{49}$ using absolute measurements of gain and loss in luminal diameter to reflect mechanical wall injury and restenosis respectively. In addition, a pathological study from the Mayo Clinic, ${ }^{62}$ of an already well documented porcine model ${ }^{63}$ showed (like the clinical study above) a proportional neointimal response to graded vessel wall injury and found that absolute neointimal thickness was more closely related to the coronary artery injury than was percentage diameter stenosis. These studies further support the contention that categorical restenosis definitions are inherently limited in their ability to describe the process of luminal renarrowing after interventions and that quantitative measurements of luminal gain by intervention and loss during follow up are the ideal angiographic correlates of wall injury and intimal hyperplasia.

Ellis and Muller, in an editorial comment on these two studies, recommended the use of absolute measurements, rather than percentage diameter stenosis as a primary angiographic end point for clinical trials. ${ }^{50}$ In addition (having pointed out that a change of $0.72 \mathrm{~mm}$ has no physiological meaning as a definition of restenosis, unless corrected for the diameter of the reference segment) they recommended normalisation for the diameter of the adjacent vessel at the time of intervention if interventions are carried out in vessels of widely varying calibre. We too ${ }^{48}$ had recognised the limitations of using a change in minimal luminal diameter of $0.72 \mathrm{~mm}$ as a criterion for significant change in luminal diameter-that is, restenosis-which, it must not be forgotten, was developed in the early years of quantitative angiography..$^{23}$ This is why we introduced the concepts of "relative gain", "relative loss", and "net gain index" to describe the immediate and long term angiographic outcome of intervention by any device on a vessel of any size.

In addition to the actual degree of injury to the vessel wall (relative gain in luminal diameter) caused at PTCA, the vessel size itself may have an important influence on "restenosis" (relative loss) which can be characterised by plotting relative gain and relative loss against the vessel size. A threshold of $3.5 \mathrm{~mm}$ emerges for the vessel size: vessels with a larger diameter showed a significantly smaller relative loss $\left(\mathrm{p}<0.05^{53}\right)$ - that is, less restenosis, during follow up. Whether this occurrence is a function of decreasing relative gain with increasing vessel size (even though there is no statistically significant difference in relative gain between vessels smaller and larger than $3.5 \mathrm{~mm}$ ) or is independently related to vessel size itself is not yet clear though logic suggests an interrelation. The application of one of the most frequently used traditional, categorical criteria for restenosis ( $>50 \%$ diameter stenosis) to these data identified no relation between the restenosis rate and either luminal gain at intervention or vessel $\operatorname{size}^{53}$ : a further illustration of the limitations of this type of approach. Because other groups ${ }^{71364}$ used categorical criteria for restenosis and evaluated results according to changes in restenosis rates they did not recognise the association between the proportional luminal improvement after intervention and subsequent deterioration during follow up, despite the use of quantitative angiographic $^{13}$ or validated user-dependent ${ }^{7}$ techniques and sophisticated statistical analyses.

The relation between relative gain and relative loss achieved with other percutaneous coronary revascularisation devices is being studied but in the light of available evidence from clinical studies from our own institution $^{1433356061}$ and others, ${ }^{16} 17$ and the previously mentioned Mayo Clinic experience in a stented porcine model, ${ }^{62}$ there is no reason to expect anything other than a similar or perhaps even stronger proportional relation.

\section{Clinical implications of the paradox}

If the "restenosis" phenomenon (angiographically represented by the relative loss) is related to or dependent on the degree of wall injury (relative gain) or the vessel size or both, this information has an important bearing, not only on clinical trails but also for clinical decision making in individual patients. It suggests that the minimal luminal diameter and reference diameter of a "culprit" coronary artery lesion should be accurately measured as an absolute value and be considered with other variables before treatment. As facilities for online digital subtraction quantitative coronary angiography become more widespread it may become possible to reduce the expected longterm relative loss associated with a therapeutic intervention in individual patients by calculation and careful achievement of a moderate relative gain, based on mean values derived from large clinical studies (which should be available in the near future) and by resisting the temptation to aim for a "perfect" angiographic result. 


\section{Randomised studies: minimal luminal diameter at follow up as the ultimate end point}

Randomised clinical trials are now in progress objectively to compare the long-term benefit of current treatments. Results are eagerly awaited, but how will they be presented? In a randomised population it is assumed that baseline characteristics are similar, in particular the minimal diameter and vessel size of treated lesions. However, the innate differences in the immediate luminal improvements attainable with different treatments and the subsequent deterioration in luminal dimension during follow up suggest that it may not be correct to use the "within patient change in minimal luminal diameter" (that is, the change in minimal luminal diameter from immediately post-intervention to follow up) to compare the various interventions in randomised trials. This argument can be further extended to trials of the pharmacological prevention of restenosis after PTCA. To judge the relative merits of new pharmacological approaches (or new interventional devices) to prevent restenosis in randomised populations the simplest, most objective, and meaningful measurement may be minimal luminal diameter at follow up as the ultimate end point of treatment.

\section{Conclusion}

It seems that the greater the relative gain achieved by an intracoronary intervention the greater the subsequent relative loss. This is certainly food for thought for interventional cardiologists, those considering arming themselves with the latest device, and indeed patients (and doctors) with obstructive coronary artery disease contemplating their options.

We suggest that the future of transluminal revascularisation will most likely be shaped and determined by a combined approach of advances in molecular biology or genetic engineering to prevent or control the tissue response to vessel wall injury after intervention rather than simply by altering existing (or introduction of new) therapeutic devices to achieve greater increases in luminal dimensions at intervention. As the search for a solution continues, we propose the matching technique as a temporary surrogate for randomised studies, and the use of relative gain, relative loss, and net gain index as a unifying quantitative angiographic approach to the assessment and comparison of all interventions-pharmacological, mechanical, thermal, or chemical.

DPF is a recipient of the Irish Heart Foundation Travelling Fellowship in Cardiology 1991.

1 Gruentzig AR, Myler RK, Hanna ES, Turina MI. Transluminal angioplasty of coronary-artery stenosis [Abstract]. Circulation 1977;56 (suppl II):84.

2 Thornton MA, Gruentzig AR, Hollman Y, King BS, Douglas JS. Coumadin and aspirin in the prevention of Douglas JS. Coumadin and aspirin in the prevention of
recurrence after transluminal coronary angioplasty: a recurrence after transluminal coronary ang
randomized study. Circulation 1984;69:721-7.

3 Leimgruber PP, Roubin GS, Hollman J, et al. Restenosis after successful coronary angioplasty in patients with after successful coronary angioplasty in patie

4 Holmes DR Jr, Vliestra RE, Smith HC, et al. Restenosis after percutaneous transluminal coronary angioplasty: a report from the PTCA Registry of the National Heart, Lung and Blood Institute. Am J Cardiol 1984;53:77-81.

5 Corocos T, David PR, Val PG, et al. Failure of diltiazem to prevent restenosis after percutaneous transluminal coronprevent restenosis after percutaneous transluming

ary angioplasty. Am Heart J 1985;109:926-31. coronary angioplasty: clinical and angiographic follow-up. J Am Coll Cardiol 1987:10:246-52.

7 Hirshfeld JW, Schwartz SS, Jugo R, et al. Restenosis after coronary angioplasty: a multivariate statistical model to relate lesion and procedural variables to restenosis. $J A m$ Coll Cardiol 1991;18:647-56.

8 Reis GJ, Boucher TM, Sipperly ME, et al. Randomised trial of fish oil for prevention of restenosis after coronary angioplasty. Lancet 1989;ii:177-181.

9 Meyer J, Schmitz HJ, Kiesslich T, et al. Percutaneous transluminal coronary angioplasty in patients with stable and unstable angina pectoris: analysis of early and late results. Am Heart J 1983;106:973-80.

10 Fleck E, Dacian S, Dirschinger J, Hall D, Rudolph W. Quantitative changes in stenotic coronary artery lesions during follow up after PTCA [Abstract]. Circulation during follow up after

11 Serruys PW, Luijten $\mathrm{HE}$, Beatt $\mathrm{KJ}$, et al. Incidence of restenosis after successful angioplasty: a time related phenomenon: A quantitative angiographic study in 342 consecutive patients at 1, 2, 3 and 4 months. Circulation 1988;77:361-71.

12 Nobuyoshi M, Kimura T, Nosaka H, et al. Restenosis after successful percutaneous transluminal coronary angioplasty: serial angiographic follow-up of 299 patients. J Am Coll Cardiol 1988;12:616-23.

13 Bourassa MG, Lesperance J, Eastwood C, et al. Clinical, physiologic, anatomic, and procedural factors predictive of restenosis after percutaneous transluminal coronary angioplasty. J Am Coll Cardiol 1991;18:368-76.

14 Serruys PW, Strauss BH, van Beusekom HM, van der Giessen WJ. Stenting of coronary arteries: has a modern Pandora's Box been opened? J Am Coll Cardiol 1991; 17:143-54.

15 Umans VA, Strauss BH, Rensing BJ, de Jaegere P, de Feyter PJ, Serruys PW. Comparative angiographic quantitative PJ, Serruys PW. Comparative angiographic quantitative analysis of the immediate efficacy of coronary atherectomy
with balloon angioplasty, stenting, and rotational ablation. with balloon angioplasty, stenting

16 Karsch KR, Haase KH, Voelker W, Baumbach A, Mauser $M$, Seipel L. Percutaneous coronary excimer laser angioplasty in patients with stable and unstable angina pectoris Acute results and incidence of restenosis during 6-month follow-up. Circulation 1990;81:1849-59.

17 Bertrand ME, Lablanche JM, Leroy F, et al. Percutaneous transluminal coronary rotational ablation with rotablato (European experience). Am J Cardiol 1992;69:470-74.

18 Reiber JHC, Boorman S, Tan HS, et al. A cardiac image analysis system. Objective quantitative processing angiocardiograms. Proc Comp Cardiol 1978:239-42.

19 Reiber JHC, Booman F, Tan HS, et al. Computer processing of coronary occlusions from X-ray arteriograms. Proceedings VI International Conference on Information 79-92.

20 Serruys PW, Booman F, Troost GJ, et al. Computerized quantitative coronary angiography applied to percuta-
neous transluminal coronary angioplasty: advantages and neous transluminal coronary angioplasty: advantages and
limitations. In: Kaltenbach M, Rentrop P, Gruentzig AR, limitations. In: Kaltenbach M, Rentrop P, Gruentzig AR, eds. Transluminal coronary angioplasty and intraVerlag, 1982:110-24

21 Serruys $P W$, Wijns W, van den Brand $M$, et al. Is transluminal coronary angioplasty mandatory after successful thrombolysis? A quantitative angiographic study. Br Heart J 1983;50:257-65.

22 Serruys PW, Reiber JHC, Wijns W, et al. Assessment of percutaneous transluminal coronary angioplasty by quantitative coronary angioplasty: diameter versus densitometric area measurements. Am J Cardiol 1984, 54:482.

23 Reiber JHC, Serruys PW, Kooijman CJ, et al. Assessment of short-, medium-, and long-term variations in arterial short-, medium-, and long-term variations in arterial
dimensions from computer assisted candidate of coronary dimensions from computer assisted candidat
cineangiograms. Circulation 1985;71:280-8.

24 Wijns W, Serruys PW, Reiber JHC, et al. Quantitative angiography of the left anterior descending coronary artery: correlation with pressure gradient and results of exercise thallium scintigraphy. Circulation 1985;71:273-9.

25 Serruys PW, Wijns W, Geuskens R, de Feyter P, van den Brand $M$, Reiber JHC. Pressure gradient, exercise thallium 201 scintigraphy, quantitative coronary cineangiography: In what sense are these measurements related? In: Reiber JHC, Serruys PW, eds. State of the art in quantitative coronary arteriography. Dordrecht, Boston, Lancaster: Martinus Nijhoff, 1986:251-70.

26 Zijlstra F, van Ommeren J, Reiber JHC, Serruys PW. Does quantitative assessment of coronary artery dimensions predict the physiological significance of a coronary stenosis? Circulation 1987;75:1154-61.

27 Beatt KJ, Luijten HE, de Feyter PJ, et al. Change in diameter of coronary artery segments adjacent to stenosis after percutaneous transluminal coronary angioplasty: after percutaneous transluminal coronary angioplasty: failure of percent diameter stenosis measurement to refect Coll Cardiol 1988;12:315-23.

28 Serruys PW, Juilliere Y, Bertrand ME, Puel J, Rickards A, Sigwart U. Additional improvement of stenosis geometry 
in human coronary arteries by stenting after balloon dilation: a quantitative angiographic study. $\mathrm{Am} J$ Cardio 1988;61:71-6.

29 Reiber JHC, Serruys PW. Quantitative coronary angiography. In: Marcus ML, Schelbert HR, Skorton DJ, Wol GI, eds. Cardiac imaging, a companion to Braunwalds heart disease. New York: Saunders, 1991:211-80.

30 Strauss BH, Juilliere Y, Rensing BJ, Reiber JHC, Serruys PW. Edge detection versus densitometry for assessin coronary stenting quantitatively. Am J Cardiol 1991; 67:484-90.

31 Umans VA, Strauss BH, de Feyter PJ, Serruys PW. Edge detection versus videodensitometry for quantitative angiographic assessment of directional coronary atherectomy. Am J Cardiol 1991;68:534-9.

32 Serruys PW, Umans VA, Serruys PW, van Suylen RJ, de Feyter PJ. Percutaneous directional coronary atherectomy: short-term clinical and angiographic results. tomy: short-term clinica

33 Serruys PW, Strauss BH, Beatt KJ, et al. Angiographic follow-up after placement of a self expanding coronar stent. N Engl J Med 1991;324:13-7.

34 de Feyter PJ, Serruys PW, Davies MJ, Richardson P, Lubsen J, Oliver MF. Quantitative coronary angiography to measure progression and regression of coronary atherosclerosis. Values, limitations and implications for clinical trials. Circulation 1991;84:412-23.

35 Strauss BH, Serruys PW, de Scheerder IK, et al. A relative risk analysis of the angiographic predictors of restenosis within the coronary Wallstent. Circulation 1991:84: 1636-43.

36 Fleming RM, Kirkeeide RL, Smalling RW, Gould KL Patterns in visual interpretation of coronary angiograms as detected by quantitative coronary angiography. $J \mathrm{Am} \mathrm{Coll}$ detected by quantitative
Cardiol 1991;18:945-51.

37 Gould KL, Lipscomb K, Hamilton GW. Physiological basi for assessing critical coronary stenosis: instantaneous flow response and regional distribution during coronary hyperaemia as measure

38 Nissen SE, Gurley JC, Grines CL, et al. Intravascular ultrasound assessment of lumen size and wall morpholog in normal subjects and patients with coronary artery disease. Circulation 1991;84:1087-99.

39 Arnett EN, Isner JM, Redwood DR, et al. Coronary artery narrowing in coronary heart disease: comparison of cineangiographic and necropsy findings. Ann Int Med 1979;91:350-6.

40 Glagov S, Weisenberg E, Zarens CK, et al. Compensatory enlargement of human atherosclerotic coronary arteries. N Engl J Med 1987;316:1371-5.

41 Smucker ML, Kil D, Howard PF, Sarnat WS. "Whole artery restenosis" after coronary atherectomy: a quantitative an

42 Klocke F. Measurements of coronary blood flow and degree of stenosis: current clinical implications and continuin uncertainties. J Am Coll Cardiol 1983;1:31-41.

43 Gould KL. Identifying and measuring severity of coronary artery stenosis. Quantitative coronary arteriography and positron emission tomography. Circulation 1988;78: $237-45$.

44 Serruys PW, Rutsch W, Heyndrickx GR, et al. Prevention of restenosis after percutaneous transluminal coronary angioplasty with Thromboxane A2 receptor blockade. A randomized, double-blind, placebo controlled trial. Circulation 1991;84:1568-81.

45 The Mercator Study Group. Does the new angiotensin converting enzyme inhibitor cilazapril prevent restenosis after percutaneous transluminal coronary angioplasty?
The results of the Mercator study: a multicentre The results of the Mercator study: a multicentre randomized double-blin

46 Hermans WRM, Rensing BJ, Paameyer J, Serruys PW. Experiences of a quantitative coronary angiographic core laboratory in restenosis prevention trials. In: Reiber JHC, Serruys PW, eds. Advances in quantitative coronary arteriography. Dordrecht: Kluwer Academic Publishers, 1992 (in press)

47 Popma JJ, Califf RM, Topol EJ. Clinical trials of restenosi following angioplasty. Circulation 1991;84:1426-37.

48 Beatt KJ, Serruys PW, Hugenholtz PG. Restenosis afte coronary angioplasty: new standards for clinical studies. $J$ Am Coll Cardiol 1990;15:491-8.

49 Beatt KJ, Serruys PW, Luijten HE, Rensing BJ Suryapranata $H$, de Feyter $P$, van den Brand $M$, Laarman GJ, Roelandt J. Restenosis after coronary angioplasty: the paradox of increased lumen diameter and restenosis. $J$ Am Coll Cardiol 1992;19:258-66.

50 Ellis SG, Muller DWM. Arterial injury and the enigma of restenosis. J Am Coll Cardiol 1992;19:275-7.

51 Rensing BJ, Hermans WR, Vos J, et al. Quantitative angiographic risk factors of luminal narrowing after coronary balloon angioplasty using balloon measurements to reflect stretch and elastic recoil at the dilatation site. $A m$ $J$ Cardiol 1992;69:584-91.

52 Rensing BJ, Hermans WR, Deckers JW, de Feyter PJ, Tijssen JGP, Serruys PW. Luminal narrowing after percutaneous transluminal coronary balloon angioplasty follows a near Gaussian distribution. A quantitative angiographic study in 1445 successfully dilated lesions. $J$ Am Coll Cardiol 1992;19:939-45.

53 Hermans WR, Rensing BJ, Kelder JC, de Feyter PJ, Serruys PW. Postangioplasty restenosis rate between segments of the major coronary arteries. Am J Cardiol 1992;69: 194-200.

54 Nobuyoshi M, Kimura T, Ohishi $\mathrm{H}$, et al. Restenosis after percutaneous transluminal coronary angioplasty: pathologic observations in 20 patients. J Am Coll Cardiol 1991;17:433-9.

55 Strauss BH, van Suylen RJ, Umans VA, et al. Directional atherectomy for treatment of restenosis within coronary Soll Cardiol (in press)

56 Clowes AW, Reidy MA, Clowes MM. Mechanisms of stenosis after arterial injury. Lab Invest 1983;49:208-15.

57 Forrester JS, Fishbein M, Helfant R, Fagin J. A paradigm for restenosis based on cell biology: clues for the develop ment of new preventive therapies. J Am Coll Cardio 1991;17:758-69.

58 Kuntz RE, Safien RD, Levine MJ, Reis GJ, Düer DJ, Baim DS. Novel approaches to the analysis of restenosis after the use of three new coronary devices. $\mathrm{J} \mathrm{Am} \mathrm{Coll} \mathrm{Cardiol}$ 1992;19:149-99.

59 Serruys PW, Rensing BJ, Luijten HE, Hermans WR, Beat $\mathrm{KJ}$. Restenosis following coronary angioplasty. In: Meier B, ed. Interventional cardiology. Toronto, Lewiston, NY, Bern, Gottingen, Stuttgart: Hogrefe and Huber, 1990: 79-115.

60 Umans VA, Beatt KJ, Rensing BJ, Hermans WR, de Feyter PJ, Serruys PW. Comparative quantitative angiographic
analysis of directional coronary atherectomy and balloon angioplasty: a new methodologic approach. $\mathrm{Am} \mathrm{J}$ Cardio 1991;68:1556-63.

61 de Jaegere $P$, Strauss BH, de Feyter $P$, Suryapranata $H$, van den Brand $M$, Serruys $P W$. Stent versus balloon angioplasty; Matching based on QCA, a surrogate for randomized studies? [Abstract]. Circulation 1991;84:0782.

62 Schwartz RS, Huber KC, Murphy JG, et al. Restenosis and the proportional neointimal response to coronary artery injury: results in a porcine model. J Am Coll Cardiol 1992;19:267-74.

63 Schwartz RS, Murphy JG, Edwards WD, Camrud AR, Vliestra RE, Holmes DR. Restenosis after balloon angioplasty. A practical proliferative model in porcine coronary plasty. A practical proliferative model

64 Kuntz R, Hinohara T, Safian R, Simpson J, Baim D. Restenosis differences between atherectomy and stenting are explained largely by vessel selection [Abstract]. Circulation 1991;84. 